\title{
Exploration and Analysis on the Reform of Basketball Teaching in Colleges and Universities
}

\author{
XiaoQian Yue \\ Chengdu Medical College, Chengdu, Sichuan, China
}

Keywords: Colleges and universities; Basketball; Teaching reform; Method innovation.

\begin{abstract}
The reform of basketball teaching is the inevitable requirement of the development of education, which can effectively make the basketball course more interesting and promote students' physical and mental health development. At present, there are lots of problems in basketball teaching of colleges and universities that need to be reformed and innovated such as the shortage of teaching resources, the unitary teaching method and unreasonable evaluation system. Therefore, the basketball teaching goals of colleges and universities should be pinpointed, the learning enthusiasm of the students should be improved, the teaching resources should be enriched, the subject status of students in teaching should be respected. What's more, we should improve the evaluation system while innovating the teaching methods, and actively carry out various extracurricular teaching activities.
\end{abstract}

\section{Introduction}

Basketball is a popular sport among college students and is an important part of sports teaching in colleges and universities. It is the original intention of colleges and universities to offer basketball lessons for students to learn about basketball knowledge, to improve their physical fitness and to learn basketball sportsmanship. However, due to the limitation of various factors and the existence of a series of reasons, the practical effect of college basketball teaching has not been ideal. Thus it is urgent to innovate teaching methods and reform the teaching mode. How to take actions to promote the healthy development of basketball teaching is a question that is worthy of further consideration.

\section{Significance of the Reform of Basketball Teaching in Colleges and Universities}

With the expansion of college enrollment, more and more teenagers go to colleges and universities. With the increase of the young students, basketball, as an interesting and competitive group game, attracts more and more attention. The voice of reforming basketball teaching is getting louder. The survey shows that over the past decade, the number of college students in our country has increased by nearly 50 percent. Half of the students hope that the teaching mode of basketball should be optimized, the teaching resources of basketball should be expanded, and the professional and recreational development of basketball should be both realized. In the aspect of colleges and universities, they hope to improve the teaching quality through the teaching reform of basketball, and help students construct good physique and the idea of lifelong sports.

The reform of basketball teaching can promote students' physical and mental health. The focus of reform is to solve problems in traditional teaching methods. College students are more flexible in their study time and are more sensitive to the physical and mental pleasure brought by sports. By optimizing teaching methods, students' knowledge of basketball and their basketball skills can be improved more quickly, and their perception ability toward the basketball teaching will be strengthened. The traditional teaching doesn't value the students' feelings about the game itself, and ignores the students' subject status. The teaching reform can not only strengthen students' physical comprehensive quality, but also enhance their interest in basketball learning. Traditional basketball teaching is relatively uninteresting. Many students, especially female students, have participated in basketball courses without taking basketball as a long-term after-school exercise. Through teaching 
reform, more advanced teaching methods and teaching forms are applied to the teaching process. The basketball course will be more inclusive, more interesting and more conducive to students' learning and teachers' teaching. In addition, the implementation of teaching reform is also conducive to the development and growth of relevant personnel and related departments. For the problems arising from the reform process, the teacher can communicate with students, and then give the feedback to the teaching management department, so as to promote the optimization and improvement of the teaching management plan. At the same time, the direction of the teaching reform and the key emphasis in work at the next stage can be quite explicit. With the constant update of the teaching plan, the enrichment of teaching methods, students are able to maintain the freshness of basketball teaching, and many problems existing in traditional teaching can be effectively solved.

\section{Problems existing in college basketball teaching}

The Lack of Teaching Resources. Teaching activities need to rely on certain teaching resources. The lack of teaching resources and the insufficient hardware facilities are the important factors restricting basketball teaching. Basketball teaching is divided into two parts: theoretical teaching and practical teaching. The practical teaching occupies a significant proportion, which means the teaching rely much on the basic teaching resources, such as basketball courts and equipment. In recent years, the enrollment scale of domestic colleges and universities has been expanding, and the court and equipment resources of basketball teaching have become increasingly tense. The lack of courts and equipment directly influences the participation of students in practical teaching. It is still a common phenomenon that a group of students share one basketball, one basket and one basketball court. The lack of hardware facilities directly lengthens the waiting time of students during the practical teaching of basketball, weakens the physical training effect of PE lessons, and also restrains their interest in basketball learning. In addition, the lack of teaching resources also influences the diversification of teaching methods to some extent. Many teaching methods that need to be realized by teaching tools are difficult to realize, and the disadvantages of traditional teaching mode are inevitable.

The Single Teaching Method. According to the new syllabus of physical education, in order to strengthen the interaction between teachers and students, students and students, teachers should use more diversified and more personalized teaching methods in the basketball teaching process, so that more students can join in basketball activities, learn basketball knowledge, and strengthen their physical quality. But in practice, the teaching method of basketball teaching in colleges and universities is still single. The most common method is still "teacher demonstration-- student imitation". The inertia of traditional teaching methods is still strong. The application of modern teaching strategies, such as situational teaching and cooperative teaching, is still very few in the field of basketball teaching. The single teaching method has a direct relation with the backward teaching ideas. A lot of PE teachers are relatively conservative. They lack the consciousness of using new teaching methods actively. They also don't know how to guide students to learn independently. They are unable to effectively stimulate the students' interest in learning basketball. All the reasons above lead to low quality and slow development of basketball teaching. Some colleges and universities offer only a few basketball courses which cannot satisfy students' objective demands of learning basketball. Except adding lesson periods, the teaching methods must be innovated and the teaching efficiency must be improved too.

Imperfect Assessment System. The assessment method used in colleges and universities is the comprehensive evaluation method, which depends on students' physical performance, theoretical knowledge, skill levels, usual performance and other factors. This kind of assessment is common and has its own advantages, but in some aspects it is not consistent with the actual situation of basketball teaching. For example, some teachers look down upon the teaching of basketball theory, and blindly focus on the teaching of the techniques and tactics, which is obviously not conducive to the development of students' comprehensive quality. In addition, the current assessment system often neglects students' individual differences. In fact, basketball is a sport that requires certain physical conditions. The different height, weight, physical fitness and physical flexibility will all affect students' performance. At the same time, different students have different bases of basketball. Some 
students start from a lower starting point. Even if they make great progress, it is difficult to meet the standard requirements in accordance with the current evaluation method. It is clear that the current assessment system is imperfect.

\section{The Effective Path of the Reform of Basketball Teaching in Colleges and Universities}

Pinpoint Teaching Goals and Cultivate Students' Interest in Learning. In order to achieve the expected teaching results, and ensure the direction of the teaching activities, teachers should first pinpoint teaching goals of basketball teaching. The teaching should be goal-oriented and embody the goals. Many teachers treat basic techniques and tactics as the core of basketball teaching. In the teaching process, they focus on the teaching of poses, footwork, ball control, tactics and teamwork, etc. The content above is the standard content of junior athletes' primary training, which has the value of learning, but cannot be treated as the core of teaching. In reality, students need basketball practice more. Without practice, students can't have a profound understanding of basketball theory, and they won't really be interested in basketball. Therefore, teachers should pinpoint the teaching goals at the beginning of the semester, and then embody the goals, which means the teaching plan should be well prepared. At the same time, it is important to cultivate students' interest and help students develop the habit of playing basketball consciously. In addition, it is also important to help students develop the consciousness of lifelong sports and to make basketball a lifelong hobby for students. It is a macro goal of setting basketball courses in colleges and universities.

Expand Teaching Resources and Highlight Students' Subject Status. Firstly, we should solve the problem of insufficient teaching resources in basketball. On the one hand, colleges and universities should give more support to basketball teaching, allocate funds to purchase sports equipment, build basketball venues, and increase the per capita occupancy of students' teaching resources. If it is impossible for colleges and universities to finance for the construction of stadiums and equipment in the short term, then teachers should optimize teaching strategies and improve the utilization rate of existing teaching resources. In the case of lack of courts and equipment, teachers can divide students into two groups, a group to carry out physical training, a group to carry out the training with equipment. The two groups alternates so that it the waiting time for students can be reduced, and the efficiency of can be increased. There are many other ways like this. For example, when it cannot be guaranteed that two students share one ball, then the teacher can divide students into several groups and number the students one by one. The student with the ball should pass it to the student with the specific number. It is called "passing by numbers". It can both strengthen their passing skill and improve their reaction skill.

Basketball teaching should respect students' subject status, stimulate their interest in learning basketball knowledge and carrying out lifelong physical training, which is conducive to students' long-term development and comprehensive quality improvement. Specifically, teachers should pay attention to the recreation of basketball games and integrate them into their teaching effectively. The teaching can be more competitive and interesting in the form of games and matches, so as to make the teaching process more attractive to students. The games and matches require high for the strategy and teamwork. It can not only improve their physical ability, but also strengthen students' ability of thinking and agility, and cultivate their spirit of teamwork and cooperation. Furthermore, teachers can add some multimedia demonstration into their teaching. Students are allowed to make comments on basketball, which can strengthen their subject consciousness while highlighting the interesting teaching process.

Innovate Teaching Methods and Actively Carry Out Extracurricular Activities. The significance of teaching method innovation lies in that it can enrich the teaching process and weaken the individual difference of the students, so as to mobilize the students' enthusiasm and motivate the students to form the habit of lifelong sports. When leading students to exercise themselves, through situational teaching method, teachers can tell them some basketball related stories in the teaching process, such as the history of basketball, excellent basketball players' stories and so on. Furthermore, basketball is a team sport, thus cooperative learning is highly adaptable in basketball teaching. It can enhance students' teamwork ability and achieve the purpose of skill training and tactical training. 
Students can help each other and make progress together in the cooperative learning. In achieving the training goals, students can also get to know their sports partners. Besides, basketball teaching should avoid the egalitarianism as much as possible. Teachers should pay attention to the differences in learning ability, learning interest and innate conditions of different students. They need to teach according to their aptitude, and make the targeted teaching plan from individual differences.

From the perspective of students, it is difficult to make progress in basketball skills by relying on the limited time in class. Teachers should not only ensure the quality of teaching in class, but also encourage students to participate in extracurricular activities and play basketball consistently. Teachers should organize more friendly matches on basketball with other colleges and universities or other classes to create more practical opportunities for students in order to help students improve their basketball skills quickly. In addition, teachers should also guide students to study independently, which is to guide students to make a specific practice plan based on the reality of their own situation, and specify the content, intensity and frequency of the exercise. Students with poor physical fitness can focus on physical training, while students with poor skills can practice shooting. In this way, the disadvantages of the teaching in class can be made up by targeted extracurricular practice. Teachers should often ask about students' extracurricular practice, regularly guide students to make and modify their after-school exercise plans, strengthen the spirit inspiration of students, and encourage more students to devote themselves to the independent study.

Improve the Assessment System and Strengthen the Students' Psychological Education. The scientific assessment system can effectively improve the students' learning enthusiasm and the practical effect of basketball teaching. In the assessment of basketball teaching, we should not only exam the students' skills and abilities, but also give full consideration to their process performance and cooperation ability. Teachers should pay attention to the students' individual differences and strengthen the targeted assessment toward different students. The purpose of the assessment is to promote students' growth rather than merely make a final assessment of students' performance at a certain stage. Therefore, teachers should point out students' strengths, such as mature skills, positive attitudes, and the spirit of teamwork. They should also timely point out the shortcomings of students, such as individualism and negative mentality, in order to encourage them to face up to their own problems. For those students who have a poor base and relatively lack congenital conditions, teachers should encourage them more. Thus they can be more confident and be more active in the basketball learning and related practice. It is worth mentioning that in the teaching process, students may face some psychological problems. Teachers should strengthen the students' psychological guidance, judge whether the current teaching method is suitable to actual circumstances and can be accepted by students from the perspective of students. Different students will show different learning status to the same basketball teaching, and give different feedback of the teaching information. The information is an important standard for teachers to check whether the teaching method is effective and the teaching rhythm is suitable.

The reform of basketball teaching in colleges and universities should face the three outstanding problems in the teaching process at present. They are the teaching resources, the teaching method and the teaching system. To carry out the reform of basketball teaching by focusing on these three problems is helpful to alleviate the core contradiction in current teaching. Furthermore, it is important to attach great importance to students' subjectivity in teaching activities and give full play to their subjective initiative, so as to promote teaching and learning, optimize the teaching platform, and improve the effectiveness of basketball teaching in colleges and universities while carrying out the teaching reform.

\section{References}

[1]Li Sheng. On the Influencing Factors and Developing Trend of Basketball Teaching Reform in Colleges and Universities [J]. Contemporary Sports Technology, 2017, 7(24):55-56.

[2]Zhe Xie. Research on Basketball Teaching Reform in Colleges and Universities under the Concept of Leisure Sports [J]. Journal of Educational Institute of Jilin Province, 2017, 33(07):114-116. 
[3]Zhong-Ren Hou, Li-Lian Liao. Exploring the Reform of Basketball Elective Courses for College Students from the Perspective of Effective Teaching - Taking Zhaoqing University as an Example [J]. Journal of Zhaoqing University, 2017, 38(02):92-96.

[4]Zhi-Wei Niu. The Influence of University Basketball Culture on Basketball Teaching Reform in Colleges and Universities [J]. Journal of Jiamusi Vocational Institute, 2017, (01):381+383.

[5]Zhen-Yong Chen. On the Innovative Thinking of Basketball Teaching Reform in Colleges and Universities [J]. Journal of Chifeng University (Natural Science Edition), 2016, 32(24):139-140.

[6]Guang-Yuan Ju. Research on the Reform of Basketball Teaching in Higher Vocational Colleges under the Background of Sunshine Sports [J]. Journal of Liaoning Teachers College (Natural Science Edition), 2016, 18(04):79-80+96. 